\title{
A ubiquitin ligase complex essential for the NF- $\kappa B$, Wnt/Wingless, and Hedgehog signaling pathways
}

\author{
Tom Maniatis ${ }^{1}$ \\ Harvard University, Department of Molecular and Cellular Biology, Cambridge, Massachusetts 02138 USA
}

Ubiquitin-dependent proteolysis by the proteasome plays an essential role in a number of key biological processes, including cell cycle progression, transcription, and signal transduction (for review, see Peters et al. 1998). In many cases the target protein is first marked for degradation or processing by phosphorylation. The phosphorylated protein is then recognized and ubiquitinated in a process that requires three proteins (Hershko et al. 1983; for review, see Hershko 1998; Peters et al. 1998). Ubiquitin is first attached to a ubiquitin-activating enzyme (E1) in an ATP-dependent reaction to form a highenergy thiolester bond. The ubiquitin is then transferred from the E1 protein to an E2 ubiquitin-conjugating enzyme, which functions in conjunction with an E3 protein to link ubiquitin to lysine residues in the targeted protein. A specific lysine residue in the conjugated ubiquitin is then attached to a second ubiquitin, and reiteration of this process results in the assembly of a polyubiquitin chain. The polyubiquitinated protein can then be recognized by the $26 \mathrm{~S}$ proteasome and degraded or processed.

\section{SCF ubiquitin ligase complexes}

E1 and E2 proteins have been identified and characterized, and the latter has been shown to comprise a family of related proteins (for review, see Peters et al. 1998). In contrast, much less is known about E3 enzymes. There are examples in which the E3 is involved directly in ubiquitin transfer (for review, see Huibregtse et al. 1998). However, in most cases E3 proteins appear to function as adapters that recruit the target protein to a complex containing an E2 enzyme, thus providing a mechanism for specificity. This mechanism is exemplified by the SCF ubiquitin ligase complex, which was initially identified in studies of the cell cycle in yeast. This complex contains the proteins Skp1, Cdc53/Cul1, and an F-box protein, as illustrated in Figure 1 (for review, see Elledge and Harper 1998; Krek 1998; Patton et al. 1998). The Cdc53/ Cull protein acts as scaffold for the complex, simultaneously interacting with a specific E2 protein and Skp1.

1E-MAIL maniatis@biohp.harvard.edu; FAX (617) 495-3537.
The Skp1 protein, in turn, interacts with the F-box protein through the F-box motif. A second protein interaction domain in the F-box protein binds specifically to the protein targeted for degradation. In the example shown, this domain is a WD40 repeat sequence although other interaction motifs have been identified in other F-box proteins. Thus, according to the 'F-box hypothesis,' distinct sets of E2s and substrates can be matched with each other through the recruitment of different F-box proteins to the SCF complex. Once the target protein is docked the E2 enzyme transfers ubiquitin from the ubiquitin-E1 complex to the target protein (Fig. 1; for review, see Elledge and Harper 1998; Patton et al. 1998).

Recently, metazoan homologs of each of the yeast SCF components have been identified. In particular, a large number of F-box proteins have been found, including $\beta$-TrCP ( $\beta$-transducin repeat-containing protein), which contains an F-box and a WD40 repeat domain (for review, see Elledge and Harper 1998; Patton et al. 1998). A number of targets of yeast F-box proteins have been identified, including certain Cdk inhibitors, $G_{1}$ cyclins, DNA replication proteins, and the transcription factor Gen4. In contrast, specific targets for the metazoan F-box proteins have not been identified. Recently, in Genes \& Development (Spencer et al. 1999; Winston et al. 1999) and elsewhere (Jiang and Struhl 1998; Yaron et al. 1998), a specific Drosophila F-box protein, Slimb, and its mammalian homolog $\beta$-TrCP have been implicated in the regulation of three different signal transduction pathways: NF-кB, Wnt/Wingless (Wnt/Wg), and Hedgehog. A common link between these pathways is the essential role of the ubiquitin proteasome pathway (Fig. 2).

\section{The NF-кB pathway}

NF- $\kappa \mathrm{B}$ and other members of the Rel family of transcriptional activator proteins are sequestered in the cytoplasm through their association with members of the IкB family of inhibitor proteins (Fig. 2A; for review, see Baeuerle and Baltimore 1996). In the case of the inhibitor $\mathrm{I} \kappa \mathrm{B} \alpha$, a variety of extracellular signals, virus infection, or ionizing radiation activate signaling pathways leading to the phosphorylation of two serine residues near the 


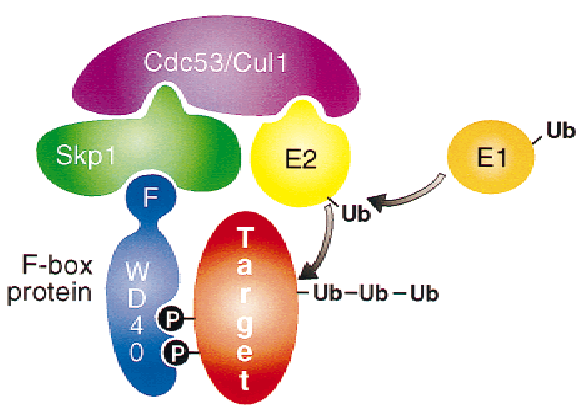

Figure 1. Composition and function of SCF ubiquitin ligase complexes (see text for details).

amino terminus of the protein (Ser-32 and Ser-36; for review, see Baldwin 1996). This modification marks the protein for ubiquitination at lysines 21 and 22 and degradation by the proteasome (for review, see Chen and Maniatis 1998). Once freed from ІкB $\alpha$, NF-кB translocates to the nucleus, where it binds to specific promoters and activates transcription. Although the upstream events in this signaling cascade have not been fully elucidated, most NF-кB-inducing signals culminate in activation of a high-molecular-weight IкB-kinase complex that phosphorylates Ser-32 and Ser-36 in IкB $\alpha$ (for review, see Maniatis 1997; Scheidereit 1998). The phosphorylation and ubiquitination of $\mathrm{I} \kappa \mathrm{B} \alpha$ can be carried out in vitro, and the reaction requires ATP, ubiquitin, E1, an E2 protein (Ubch5 or Ubch7), and a partially purified E3 activity (Alkalay et al. 1995; Chen et al. 1995, 1996). However, prior to the recent studies reviewed here, a specific IкB $\alpha$ E3 protein has not been identified.

\section{The Wnt/Wg pathway}

The ubiquitin/proteasome pathway is also involved in the regulation of the Wnt/Wg signaling pathway. The activity of the transcriptional regulatory protein TCF/ LEF-1, a terminal component of this pathway, is regulated by its association with the transcriptional coactivator $\beta$-catenin/Armadillo ( $\beta$-cat/Arm), another component of the Wnt/Wg pathway (Fig. 2B; for review, see Willert and Nusse 1998). In the absence of Wnt/Wg signaling, the $\beta$-cat/Arm protein is phosphorylated as a consequence of its association with APC (adenomatous polyposis coli), axin, and the kinase GSK3 $\beta$ (glycogen synthase kinase $3 \beta$ ). The phosphorylation sites on $\beta$-cat/ Arm are strikingly similar to those of IкB proteins (DSG $\psi \mathrm{XS}$ ), where $\psi$ is a hydrophobic residue and $S$ corresponds to the two serines that are phosphorylated (Ikeda et al. 1998). This phosphorylation is thought to target $\beta$-cat/Arm for ubiquitination and degradation by the proteasome (Aberle et al. 1997; Orford et al. 1997). When the Wnt/Wg pathway is activated, GSK3 $\beta$ is inhibited and $\beta$-cat/Arm accumulates, translocates to the nucleus, and functions as a coactivator with TCF/LEF-1. In the absence of $\beta$-cat/Arm, the TCF/LEF-1 protein functions as a repressor of downstream genes.

\section{The Hedgehog signaling pathway}

The activity of the transcriptional regulatory protein $\mathrm{Cu}$ bitus interruptus (Ci), a component of the Hedgehog (Hh) signaling pathway, is also regulated by the ubiquitinproteasome pathway (for review, see Ruiz i Altaba 1997; Ingham 1998). Normally, the $155-\mathrm{kD}$ Ci protein is part of a microtubule-bound complex containing three other proteins, Costal-2 (Cos-2), Fused (Fu), and Suppressor of fused $[\mathrm{Su}(\mathrm{fu})]$. In the absence of Hedgehog signaling, the $155-\mathrm{kD}$ Ci protein is proteolytically processed to produce a $75-\mathrm{kD}$ amino-terminal protein that is released from the complex and acts as a transcriptional repressor (Fig. 2C; Aza-Blanc et al. 1997). This processing can be blocked by proteasome inhibitors (Ingham 1998), thus implicating the ubiquitin-proteasome pathway. A precedent for such a ubiquitin-proteasome-dependent processing mechanism is provided by the NF-кB p105 protein, which is the precursor of the p50 subunit of NF-кB (Fan and Maniatis 1991; Palombella et al. 1994). Proteolytic processing of $\mathrm{Ci}$ appears to require phosphorylation by protein kinase A (PKA) (Chen et al. 1998; for review, see Ingham 1998). In the presence of the Hh protein, Ci processing is suppressed. The $155-\mathrm{kD} \mathrm{Ci}$ protein accumulates, and, by a mechanism yet to be determined, is released from the microtubule-bound complex (see Ohlmeyer and Kalderon 1998 for recent discussion and references). The intact $\mathrm{Ci}$ protein then acts as a transcriptional activator to turn on downstream genes. Thus, the common feature of all three pathways is the signaldependent phosphorylation and ubiquitination of a regulatory protein and its degradation or processing by the proteasome.

\section{Role of the $\mathrm{SCF}^{\beta \operatorname{TrCP}}$ complex}

The exciting new finding is that one SCF ligase complex $\left(\mathrm{SCF}^{\beta \mathrm{TrCP}}\right)$ may ubiquitinate the protein targets in all three signaling pathways (IкB $\alpha, \beta$-cat/Arm, and Ci). This possibility was first indicated by genetic studies in Drosophila that identified a Drosophila gene that negatively regulates both the $\mathrm{Hh}$ and $\mathrm{Wnt} / \mathrm{Wg}$ pathways (Jiang and Struhl 1998). This gene, termed Slimb (supernumerary limbs), encodes an F-box/WD40 repeat protein that bears a striking resemblance to yeast F-box proteins found in SCF complexes. In the absence of Slimb, high levels of both $\mathrm{Ci}$ and Arm accumulate in a cell-autonomous manner, and both Hh- and Wg-responsive genes are expressed ectopically. The researchers proposed that Slimb is required for the processing of $\mathrm{Ci}$ and the degradation of Arm via the ubiquitin-proteasome pathway.

Recently, Slimb was directly implicated in the NF-кB pathway by the observation that the Slimb protein is required for the activation of the Drosophila NF-кB homolog, Dorsal (Spencer et al. 1999). During dorsoventral patterning of the early Drosophila embryo, the Dorsal protein is activated specifically on the ventral side of the embryo by the Toll receptor-signaling pathway (for review, see Morisato and Anderson 1995). This pathway culminates in the degradation of the Drosophila ІкB pro- 

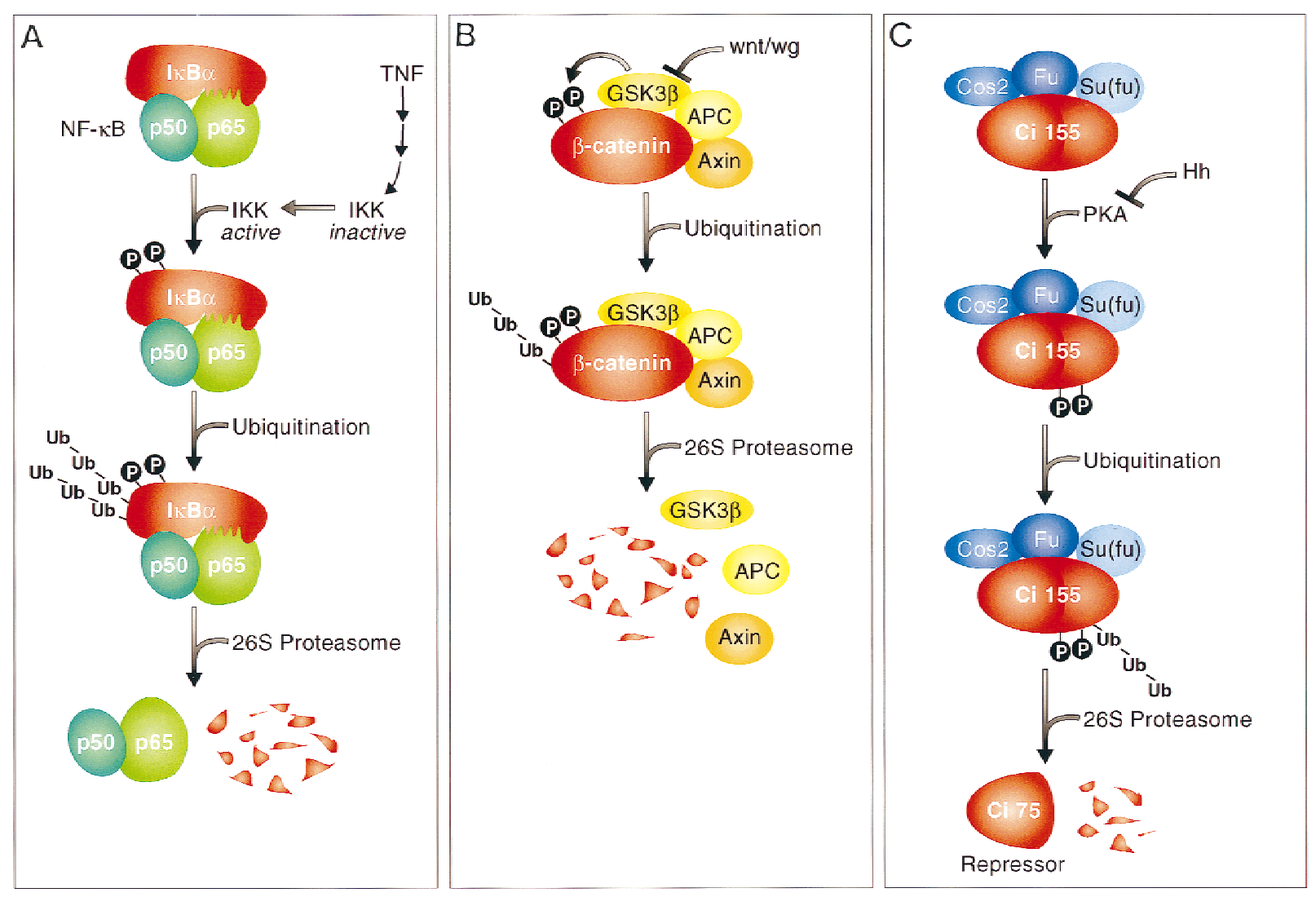

Figure 2. The role of the ubiquitin-proteasome pathway in the regulated degradation of ІкB $\alpha$ and $\beta$-cat/Arm, and the processing of Ci. (A) Degradation of ІкB $\alpha$. A variety of signals, including tumor necrosis factor- $\alpha$ (TNF- $\alpha$ ) shown here, lead to the activation of an IкB-kinase complex (IKK), which specifically phosphorylates Ser-32 and Ser-36 at the amino terminus of IкB $\alpha$. This phosphorylation marks the protein for ubiquitination at lysines 21 and 22. Polyubiquitinated IкB $\alpha$ is then recognized by the $26 \mathrm{~S}$ proteasome and degraded, resulting in the release and nuclear translocation of NF- $\mathrm{KB}$. $(B)$ Degradation of $\beta$-catenin. In the absence of Wnt/Wg, a complex of GSK3 $\beta, A P C$, and axin associates with and phosphorylates $\beta$-catenin. Although not yet demonstrated directly, this phosphorylation likely targets $\beta$-catenin for ubiquitination followed by proteasome degradation. In the presence of Wnt/Wg this process is blocked, leading to the accumulation of $\beta$-catenin, which functions as a coactivator for the transcription factor TCF/LEF-1. The $\beta$-catenin/TCF/LEF-1 complex then activates downstream genes in the Wnt/Wg pathway. (C) Processing of Cubitus interruptus (Ci). In the absence of Hh signaling, the $155-\mathrm{kD}$ Ci protein is bound to microtubules in a complex with three other proteins [cos2, Fu, and $\mathrm{Su}(\mathrm{fu})]$. PKA phosphorylates Ci 155, and this phosphorylation may target the Ci protein for ubiquitination and processing by the $26 \mathrm{~S}$ proteasome, thus generating a $75-\mathrm{kD}$ amino-terminal protein. The $\mathrm{Ci} 75-\mathrm{kD}$ protein is thought to function as a transcriptional repressor of downstream genes. In the presence of $\mathrm{Hh}$, phosphorylation of $\mathrm{Ci}$ is suppressed, possibly a consequence of inhibiting PKA (for review, see Ingham 1998).

tein, Cactus, allowing the nuclear translocation of Dorsal and the activation of downstream genes such as twist and snail. In slimb mutants, twist and snail gene expression is no longer induced on the ventral side of the embryo (Spencer et al. 1999). Thus, the F-box/WD40 protein Slimb appears to be a component of an SCF complex required for the ubiquitination of ІкB proteins, $\beta$-cat/ Arm, and Ci. However, until now, there was no direct biochemical evidence to support this model.

\section{$\beta-\operatorname{TrCP}$ is a component of the IKB ubiquitin ligase}

Independent studies from three different groups now provide compelling evidence that the $\beta$-TrCP protein, a mammalian homolog of the Drosophila Slimb protein, is indeed a component of the ІкB ubiquitin ligase (Yaron et al. 1998; Spencer et al. 1999; Winston et al. 1999). First, Ben-Neriah and his collaborators used an affinity purification approach to identify $\beta-\operatorname{TrCP}$ as a protein that binds specifically to phosphorylated IкB $\alpha$ in vitro (Yaron et al. 1998). Second, based on their finding that Slimb is required for the activation of twist and snail in Drosophila, the groups of Chen and Jiang (Spencer et al. 1999) isolated $\beta$-TrCP as a mammalian homolog of Slimb, and showed that $\beta$-TrCP specifically interacts with phosphorylated IкB $\alpha$ in vitro and in vivo. Third, the groups of Harper and Elledge and their collaborators speculated that a mammalian SCF complex might be involved in the degradation of IкB $\alpha$ and showed that in vitro translated $\beta$-TrCP binds to a 21 -amino-acid phosphopeptide of IкB $\alpha$ containing Ser-32 and Ser-36 (Winston et al. 1999). In this case, several different mamma- 
lian F-box proteins were tested, but only $\beta$-TrCP bound to phosphorylated I $\mathrm{B} \alpha$. Evidence for an in vivo function of $\beta$-TrCP was provided by the observation that a deletion mutant of $\beta$-TrCP, lacking the F-box motif, functions as a dominant negative inhibitor of NF- $\kappa \mathrm{B}$ activation (Yaron et al. 1998; Spencer et al. 1999).

Two of the groups showed that the $\beta$-TrCP protein functions as a component of an SCF complex (Spencer et al. 1999; Winston et al. 1999). Spencer et al. (1999) found that $\mathrm{I} \kappa \mathrm{B} \alpha$ and $\mathrm{Skp} 1$, the p65 subunit of NF-кB, and $\beta$-TrCP could be coimmunoprecipitated with epitopetagged $\beta$-TrCP expressed in human 293 cells treated with calyculin A (a phosphatase inhibitor that induces NF$\kappa \mathrm{B})$. The association of $\mathrm{I} \kappa \mathrm{B} \alpha$ with Skp1 and $\beta$-TrCP was not observed in the absence of calyculin $\mathrm{A}$, showing that the phosphorylation of IкB $\alpha$ is required for its recruitment to the SCF complex. In a complementary approach, Winston et al. (1999) transfected 293 cells with plasmids expressing epitope-tagged $\beta$-TrCP, Cul1, and Skp1, and found that all three proteins could be coimmunoprecipitated. In addition, the immunoaffinity-purified complex containing these components could associate with phosphorylated IкB $\alpha$ immobilized on agarose beads. Taken together, these experiments provide strong evidence that the phosphorylation of I $\mathrm{B} \alpha$ leads to its association with an SCF complex in vivo, and that the F-box protein in this complex is $\beta$-TrCP.

The functional significance of this association was demonstrated elegantly by in vitro ubiquitination experiments using an immunopurified complex isolated from cells transfected with epitope-tagged $\beta$-TrCP (Yaron et al. 1998; Spencer et al. 1999; Winston et al. 1999). In two of the studies, specific ubiquitination of IкB $\alpha$ was observed when the $\beta$-TrCP-associated complex was incubated with a phosphorylated ІкB $\alpha / \mathrm{NF}-\kappa \mathrm{B}$ complex in the presence of ATP, recombinant E1, and the E2 protein Ubch5 (Yaron et al. 1998; Spencer et al. 1999). Thus, it appears that the SCF complex isolated from transfected 293 cells by immunoaffinity purification does not contain an E2 protein, suggesting that the E2 is bound weakly to the complex and is lost during immunopurification. It is important to note that specific Iк $\mathrm{B} \alpha$ ubiquitination was observed only when IкB $\alpha$ was bound to NF-кB, suggesting that the structure of IкB $\alpha$ in the complex is required for the recognition of $\mathrm{I} \kappa \mathrm{B} \alpha$ by the SCF complex. Ubiquitination was not observed with Ser32Ala/Ser36Ala mutants, or in the presence of the F-box deletion mutant $\beta$-TrCP that acts as a dominantnegative mutant of NF- $\mathrm{B}$ activation (Spencer et al. 1999). In addition, substitution of lysines 21 and 22 of IкB $\alpha$ blocked in vitro ubiquitination (Spencer et al. 1999; see also Scherer et al. 1995). In parallel studies Winston et al. (1999) showed that the Skp1, Cul1, and $\beta$-TrCP complex immunopurified from 293 cells did not ubiquitinate phosphorylated IкB $\alpha$, but could be complemented by the addition of yeast extracts. The yeast extracts likely contributed the E1 and E2 activities necessary for ubiquitination. Additional evidence for a role of the SCF complex in I $\mathrm{B} \alpha$ ubiquitination was provided by the observation that Skp1, Cul1, and $\beta$-TrCP copurify with
Iк $\mathrm{B} \alpha$ ubiquitinating activity from cell extracts (Winston et al. 1999), and this activity could be immunodepleted with an anti-Skp1 antibody. Taken together, these observations definitively demonstrate that an SCF complex is required for the signal-dependent degradation of IкB $\alpha$, and that the F-box protein $\beta$-TrCP functions as the specificity factor in this complex.

A hint that the same mechanism is involved in the recognition and ubiquitination of $\beta$-cat/Arm was provided by the observation that a phosphopeptide containing the GSK3 $\beta$ phosphorylation site on $\beta$-catenin can interact specifically with $\beta$-TrCP and Skp1 (Winston et al. 1999). This observation is consistent with previous studies showing that a dominant-negative F-box deletion mutant of $\beta$-TrCP results in a phenotype consistent with stabilization of $\beta$-catenin in Xenopus (Marikawa and Elinson 1998). Although additional biochemical studies are required to confirm these findings, it seems likely the $\beta$-cat/Arm is indeed ubiquitinated via the SCF complex. The possibility that the same SCF complex is required for processing the Drosophila Ci protein has yet to be demonstrated in biochemical studies. However, the observations that $\mathrm{Ci}$ processing requires the proteasome, and that Slimb mutants lead to the accumulation of $\mathrm{Ci}$, are highly suggestive of this possibility.

\section{Role of SCF ${ }^{\beta-T r C P}$ in the degradation of CD4}

An additional target of the $\mathrm{SCF}^{\beta-\mathrm{TrCP}}$ complex is the CD4 protein, through its association with the human immunodeficiency virus (HIV) protein, Vpu (Fujita et al. 1997; Margottin et al. 1998; Schubert et al. 1998). Recent studies have shown that the Vpu protein can simultaneously interact with the CD4 protein and $\beta$-TrCP to form a ternary complex, which targets CD4 for proteolysis (Margottin et al. 1998). The Vpu/ $\beta$-TrCP interaction, which occurs through the WD40 repeats of $\beta$-TrCP, requires the phosphorylation of two serine residues in $\mathrm{Vpu}$. These serines are located within a sequence motif remarkably similar to that containing the phosphorylation sites in IкB $\alpha$ and $\beta$-cat/Arm (Margottin et al. 1998). In addition, the Vpu-dependent degradation of CD4 requires the ubiquitin pathway, and proteasome inhibitors block this degradation (Fujita et al. 1997; Schubert et al. 1998). These observations are consistent with the view that Vpu carries the CD4 protein to the SCF complex where CD4 is ubiquitinated and thus targeted for degradation by the proteasome (Margottin et al. 1998).

\section{Medical implications}

The discovery of the ubiquitin ligase complex for $\mathrm{I} \kappa \mathrm{B} \alpha$ is an important advance in understanding the mechanisms of regulated proteolysis, and it provides new insights into signaling pathways of considerable medical interest. NF- $\kappa \mathrm{B}$ is a key regulatory protein in the immune and inflammatory responses, and the signaling pathway leading to its activation provides targets for the development of drugs to treat inflammatory diseases. In this regard, 
the finding that the $\mathrm{SCF}^{\beta-\mathrm{TrCP}}$ complex can ubiquitinate several different proteins is a disappointment, as the development of selective inhibitors of the complex will be difficult. Of particular concern would be the effects of $\mathrm{SCF}^{\beta-\mathrm{TrCP}}$ inhibitors on $\beta$-catenin accumulation. Mutations in APC and $\beta$-catenin that lead to the accumulation of the $\beta$-catenin protein are associated with a number of different human cancers. It is not surprising that many of the oncogenic mutations in $\beta$-catenin localize to the amino acid sequences required for its phosphorylation and ubiquitination (see Winston et al. 1999 and He et al. 1998 for discussion and references). At least one of the oncogenic effects of $\beta$-catenin is its ability to function as a coactivator with LEF-1/TCF to promote c-myc gene expression (He et al. 1998). Thus, inhibitors of the $\mathrm{SCF}^{\beta-\mathrm{TrCP}}$ complex would be expected to increase the level of c-myc expression and possibly lead to oncogenic transformation. At present, the most specific targets for the inhibition of NF- $\mathrm{B}$ activity are the components of the high molecular weight ІкВ kinase complex, a conclusion supported by the recent finding that IKK $\beta$, one component of this complex, is inhibited by aspirin (Yin et al. 1998).

\section{References}

Aberle, H., A. Bauer, J. Stappert, A. Kispert, and R. Kemler. 1997. $\beta$-Catenin is a target for the ubiquitin-proteasome pathway. EMBO I. 16: 3797-3804.

Alkalay, I., A. Yaron, A. Hatzubai, A. Orian, A. Ciechanover, and Y. Ben-Neriah. 1995. Stimulation-dependent IкB $\alpha$ phosphorylation marks the NF-кB inhibitor for degradation via the Ub-proteasome pathway. Proc. Nat1. Acad. Sci. 92: 10599-10603.

Aza-Blanc, P., F.-A. Ramírez-Weber, M.-P. Laget, C. Schwartz, and T.B. Kornberg. 1997. Proteolysis that is inhibited by Hedgehog targets Cubitus interuptus protein to the nucleus and converts it to a repressor. Cell 89: 1043-1053.

Baeuerle, P.A. and D. Baltimore. 1996. NF-кB: Ten years after. Cell 87: 13-20.

Baldwin, A.S. 1996. The NF-кB and IкB proteins: New discoveries and insights. Annu. Rev. Immunol. 14: 649-681.

Chen, Y., N. Gallaher, R.H. Goodman, and S.M. Smolik. 1998. Protein kinase A directly regulates the activity and proteolysis of Cubitus interruptus. Proc. Natl. Acad. Sci. 95: 23492354.

Chen, Z.J. and T. Maniatis. 1998. Role of the ubiquitin-proteasome pathway in NF-кB activation. In Ubiquitin and the biology of the cell (ed. J.-M. Peters, J.R. Harris, and D. Finley), pp. 303-322. Plenum Press, New York, NY.

Chen, Z.J., J. Hagler, V.J. Palombella, F. Melandri, D. Scherer, D. Ballard, and T. Maniatis. 1995. Signal-induced site-specific phosphorylation targets Iк $\mathrm{B} \alpha$ to the ubiquitin-proteasome pathway. Genes \& Dev. 9: 1586-1597.

Chen, Z.J., L. Parent, and T. Maniatis. 1996. Site-specific phosphorylation of $\mathrm{I}_{\kappa} \mathrm{B} \alpha$ by a novel ubiquitin-dependent protein kinase activity. Cell 84: 853-862.

Elledge, S.J. and J.W. Harper. 1998. Proteolysis in cell cycle control and cancer. Biochem. Biophys. Acta 1377: M61-M70.

Fan, C.-M. and T. Maniatis. 1991. Generation of p50 subunit of NF- $\mathrm{B}$ by processing of p105 through an ATP-dependent pathway. Nature 354: 395-398.

Fujita, K., S. Omura, and J. Silver. 1997. Rapid degradation of
CD4 in cells expressing human immunodeficiency virus type $1 \mathrm{Env}$ and $\mathrm{Vpu}$ is blocked by proteasome inhibitors. I. Gen. Virol. 78: 619-625.

He, T.C., A.B. Sparks, C. Rago, H. Hermeking, L. Zawel, L.T. da Costa, P.J. Morin, B. Vogelstein, and K.W. Kinzler. 1998. Identification of c-MYC as a target of the APC pathway. Science 281: 1509-1512.

Hershko, A. 1998. The ubiquitin system. Past, present, and future perspectives. In Ubiquitin and the biology of the cell (ed. J.-M. Peters, J.R. Harris, and D. Finley), pp. 1-17. Plenum Press, New York, NY.

Hershko, A., H. Heller, S. Elias, and A. Ciechanover. 1983. Components of the ubiquitin-protein ligase system. Resolution, affinity purification, and role in protein breakdown. $J$. Biol. Chem. 258: 8206-8214.

Huibregtse, J.M., C.G. Maki, and P.M. Howley. 1998. Ubiquitination of the p53 tumor suppressor. In Ubiquitin and the biology of the cell (ed. J.-M. Peters, J.R. Harris, and D. Finley), pp. 323-343. Plenum Press, New York, NY.

Ikeda, S., S. Kishida, H. Yamamoto, H. Murai, S. Koyama, and A. Kikuchi. 1998. Axin, a negative regulator of the Wnt signaling pathway, forms a complex with GSK-3 $\beta$ and $\beta$-catenin

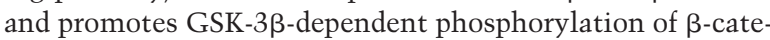
nin. EMBO J. 17: 1371-1384.

Ingham, P.W. 1998. Transducing Hedgehog: The story so far. EMBO J. 17: 3505-3511.

Jiang, J. and G. Struhl. 1998. Regulation of the Hedgehog and Wingless signaling pathways by the F-box/WD40-repeat protein Slimb. Nature 391: 493-496.

Krek, W. 1998. Proteolysis and the $\mathrm{G}_{1}-\mathrm{S}$ transition: The SCF connection. Curr. Opin. Genet. Dev. 8: 36-42.

Maniatis, T. 1997. Catalysis by a multiprotein ІкB kinase complex. Science 278: 818-819.

Margottin, F., S.P. Bour, H. Durand, L. Selig, S. Benichou, V. Richard, D. Thomas, K. Strebel, and R. Benarous. 1998. A novel human WD protein, h- $\beta \operatorname{TrCP}$, that interacts with HIV-1 Vpu connects CD4 to the ER degradation pathway through an F-box motif. Mol. Cell. 1: 565-574.

Marikawa, Y. and R.P. Elinson. 1998. $\beta$-TrCP is a negative regulator of Wnt/ $\beta$-catenin signaling pathway and dorsal axis formation in Xenopus embryos. Mech. Dev. 77: 75-80.

Morisato, D. and K.V. Anderson. 1995. Signaling pathways that establish the dorsal-ventral pattern of the Drosophila embryo. Annu. Rev. Genetics 19: 371-379.

Ohlmeyer, J.T. and D. Kalderon. 1998. Hedgehog stimulates maturation of Cubitus interuptus into a labile transcriptional activator. Nature 396: 749-753.

Orford, K., C. Crockett, J.P. Jensen, A.M. Weissman, and S.W. Byers. 1997. Serine phosphorylation-regulated ubiquitination and degradation of $\beta$-catenin. J. Biol. Chem. 272: 2473524738.

Palombella, V.J., O.J. Rando, A.L. Goldberg, and T. Maniatis. 1994. The ubiquitin-proteasome pathway is required for processing the NF- $\mathrm{kB} 1$ precursor protein and the activation of NF-кB. Cell 78: 773-785.

Patton, E.E., A.R. Willems, and M. Tyers. 1998. Combinatorial control in ubiquitin-dependent proteolysis: Don't Skp the F-box hypothesis. Trends Genet. 14: 236-243.

Peters, J.-M., J.R. Harris, and D. Finley. 1998. Ubiquitin and the biology of the cell. Plenum Press, New York, NY.

Ruiz i Altaba, A. 1997. Catching a Gli-mpse of Hedgehog. Cell 90: 193-196.

Scheidereit, C. 1998. Signal transduction. Docking ІкB kinases. Nature 395: 225-226.

Scherer, D.C., J.A. Brockman, Z. Chen, T. Maniatis, and D.W. Ballard. 1995. Signal-induced degradation of IкB $\alpha$ requires 
Maniatis

site-specific ubiquitination. Proc. Natl. Acad. Sci. 92: 11259-11263.

Schubert, U., L.C. Anton, I. Bacik, J.H. Cox, S. Bour, J.R. Bennink, M. Orlowski, K. Strebel, and J.W. Yewdell. 1998. CD4 glycoprotein degradation induced by human immunodeficiency virus type-1 Vpu protein requires the function of proteasomes and the ubiquitin conjugating pathway. I. Virol. 72: 2280-2288.

Spencer, E., J. Jiang, and Z.J. Chen. 1999. Signal-induced ubiquitination of $\mathrm{I} \kappa \mathrm{B} \alpha$ by the F-box protein, Slimb $/ \beta-\operatorname{TrCP}$. Genes \& Dev. 13: 284-294.

Willert, K. and R. Nusse. 1998. $\beta$-Catenin: A key mediator of Wnt signaling. Curr. Opin. Genet. Dev. 8: 95-102.

Winston, J.T., P. Strack, P. Beer-Romero, C. Chu, S.J. Elledge, and J.W. Harper. 1999. The SCF- $\beta^{\text {TRCP }}$ ubiquitin ligase complex associates specifically with phosphorylated destruction motifs in IкB $\beta$ and $\beta$-catenin and stimulates IкB $\alpha$ ubiquitination in vitro. Genes \& Dev. 3: 270-283.

Yaron, A., A. Hatzubai, M. Davis, I. Lavon, S. Amit, A.M. Manning, J.S. Andersen, M. Mann, F. Mercurio, and Y. Ben-Neriah. 1998. Identification of the receptor component of the IкB $\alpha$-ubiquitin ligase. Nature 396: 590-594.

Yin, M.J., Y. Yamamoto, and R.B. Gaynor. 1998. The anti-inflammatory agents aspirin and salicylate inhibit the activity of ІкB kinase- $\beta$. Nature 396: 77-80. 


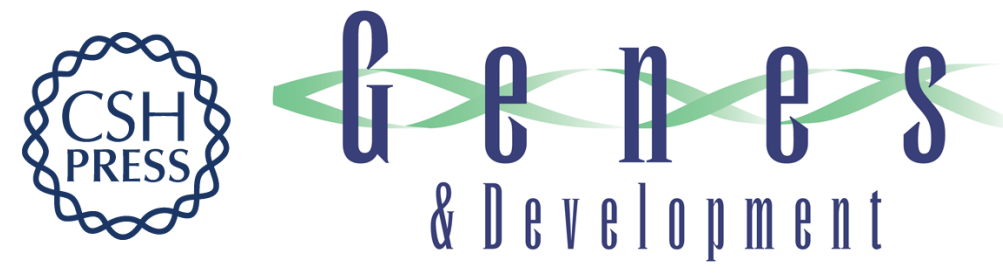

\section{A ubiquitin ligase complex essential for the NF-kB, Wnt/Wingless, and Hedgehog signaling pathways}

Tom Maniatis

Genes Dev. 1999, 13:

References This article cites 34 articles, 13 of which can be accessed free at:

http://genesdev.cshlp.org/content/13/5/505.full.html\#ref-list-1

License

Email Alerting
Service $\begin{aligned} & \text { Receive free email alerts when new articles cite this article - sign up in the box at the top } \\ & \text { right corner of the article or click here. }\end{aligned}$

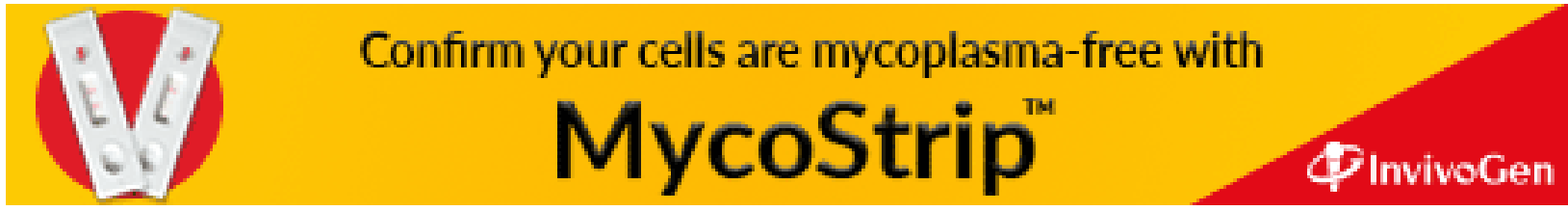

